\title{
OS DESAFIOS DOS EXPATRIADOS: O ESTABELECIMENTO DO EX- ESCRAVO WILLIAM DOUGLASS E SUA FAMÍLIA NA LIBÉRIA (1857 -
}

1866)

Tainá Elis Santos de Souza ${ }^{1}$

\begin{abstract}
Resumo: Em 1854, Dr. James Hunter Terrell, dono da fazenda 'Music Hall', em Albemarle County, na Virgínia, fez um testamento no qual expressava sua vontade de que seus escravos fossem libertos após sua morte e preferencialmente reassentados na Libéria. Em dezembro de 1856, o Dr. James Hunter Minor, o sobrinho do fazendeiro e executor do seu testamento enviou alguns dos exescravos do tio para a Libéria no navio Mary Caroline Stevens. Dentre estes, estava William Douglass, nascido nos Estados Unidos e homônimo do conhecido líder abolicionista. Assim que chegou na Monróvia, em 8 de Fevereiro de 1857, ele começou a se corresponder com Dr. James Hunter Minor relatando as dificuldades e as conquistas feitas no novo lar, bem como solicitou notícias e o envio de alguns bens dos Estados Unidos. Foram encontradas somente as correspondências enviadas por William Douglass no período de 1857 até 1866.
\end{abstract}

Palavras-chave: William Douglass, Libéria, ex-escravos, expatriação, biografia.

\begin{abstract}
In 1854, Dr. James Hunter Terrell, owner of Music Hall plantation, in Albemarle County, Virginia, has made a will which expressed his desire that his slaves were freed after his death and were preferably resettled in Liberia. In december, 1856, the Dr. James Hunter Minor, the farmer's nephew, will executor, sent some former slaves to Liberia on the ship Mary Caroline Stevens. William Douglass was among them, he borned in the Unites States and he was homonym of the known abolitionist leader. As soon as he arrived in Monrovia, on February 8th, 1857, he started to communicate through letters with Dr. James Hunter Minor, reporting his difficulties and achievements in the new home, just as requested news and the shipment of some goods from the United States. It has only been found the letters sent by William Douglass during the period between 1857 and 1866.
\end{abstract}

Keywords: William Douglass, Liberia, former slaves, expatriation, biography.

\section{Introdução}

A questão da escravidão foi um dos pontos centrais para a iniciativa de colonização norteamericana no território da Libéria. O sucesso da repatriação de ex-escravos em Serra Leoa regenerou o interesse dos negros na emigração para a África, que emergiu da incredulidade, por

1 Graduanda em História na Universidade Federal de Minas Gerais. 
parte de alguns deles e dos brancos, de uma real assimilação e integração dos ex-escravos na sociedade norte-americana. "A Libéria ofereceu a oportunidade para que os emigrantes alforriados e os nascidos livres pudessem avançar com suas habilidades sociais sem as restrições enfrentadas por aqueles que permaneceram nos Estados Unidos". ${ }^{1}$

Em 1816, foi criada a American Colonization Society (ACS), instituição que agregava financiamentos tanto de abolicionistas, quanto de escravistas, para a expatriação dos negros livres para a África, criando uma alternativa ao problema da integração racial. Originalmente a ACS foi patrocinada por instituições missionárias e de caridade, posteriormente, no entanto, estadistas e latifundiários sulistas se uniram ao projeto. ${ }^{2}$ Isso ocorreu devido ao medo que muitos donos de escravos possuíam de uma 'influência negativa' que os negros livres poderiam ter sobre os ainda escravizados. Em tese, objetivo da ACS era, através dessas expatriações, cristianizar e civilizar as populações nativas africanas a fim de prepará-las para o estabelecimento de acordos comerciais com os Estados Unidos.

No ano de 1819, depois de muita pressão dos associados, o governo de James Monroe (1817-1825) patrocinou com 100 mil dólares para a expedição da ACS que previa o estabelecimento de uma colônia norte-americana na Malaguetta Coast, o que foi oficialmente encarado como uma medida para suprimir o comércio de escravos através da criação de um novo local para o restabelecimento dos escravos recapturados pela Marinha norte-americana dos navios negreiros. $\mathrm{O}$ primeiro navio da ACS saiu dos EUA em 1820, no entanto, a alta taxa de mortalidade dos colonos devido às febres tropicais fez com que a o primeiro grupo só conseguisse se estabelecer na Libéria no ano de 1822. Durante o processo de emigração envolvendo a ACS (de 1820 até 1863), a maioria dos negros expatriados eram ex-escravos pobres do sul com suas famílias, porém havia com eles uma minoria intelectual negra, entre os quais podemos citar Edward Blyden e Alexander Crummell.

As conexões atlânticas entre Estados Unidos e Libéria foram fundamentais para o estabelecimentos de expatriados, por várias razões a Marinha norte-americana promovia a segurança contra os ataques das tribos nativas, ${ }^{3}$ transportava produtos manufaturados e alguns

1 "Liberia presented the opportunity for manumitted and freeborn emigrants to their social skills for advancement without the restrictions of racism confronted by those who remained in the United States" In: ZUBERI, Tukufu, Swing Low, Sweet Chariot: The Mortality Cost of Colonizing Liberia in the Nineteenth-Century. Chicago: University of Chicago Press, 1995. p. xviii;.

2 LOWENKOPF, Martin. Politics in Liberia: The Conservative Road to Development. Califórnia: Hoover Institution Press, 1976.

3 SICKLE, Eugene S. Van. Reluctant Imperialists: The U.S. Navy and Liberia, 1819 - 1845. Journal of the Early Republic, volume 31, nº 1, 2011, p. 107-134. 
alimentos enviados dos $\mathrm{EUA}^{4}$, e também gerenciava a rede de comércio estabelecida entre ambos os locais. A partir das cartas escritas por William Douglass, poderemos analisar essas conexões atlânticas e como ocorreu a adaptação dos negros expatriados no novo continente, visto que esse era um grande desafio devido ao clima diferente e a alta taxa de mortalidade dos emigrados.

\section{O Senhorio Terrell}

Antes de falarmos sobre a mudança de William Douglass para a Libéria é importante analisarmos as circunstâncias que o levaram para lá. O primeiro documento importante é o testamento (1854) do seu senhor James Hunter Terrell (1784 - 1856). Neste, ele manifestou a sua vontade de que todos os seus escravos fossem libertados após sua morte, sendo que eles poderiam escolher permanecer com seus familiares, para isso poderiam escolher um novo mestre, para o qual seriam vendidos por um preço nominal, mas, preferencialmente, ele gostaria que eles fossem enviados para Libéria ${ }^{5}$.

Podemos levantar duas hipóteses sobre o que motivou James Hunter Terrell a querer libertar todos os seus escravos. A família Terrell fazia parte da comunidade quaker de Albemarle County na Virgínia, e ortodoxamente os quakers se posicionaram contra a escravidão. No entanto, até a Guerra Civil, os quakers não construíram nenhuma oposição expressiva à escravidão ${ }^{6}$, pelo contrário, muitos eram senhores de escravos, como os Terrell, afinal, essa era uma fonte de dinheiro e poder no sul. As discussões sobre a escravidão tinham duas posições dentro da Sociedade Religiosa dos Amigos, havia os que acreditavam que através da educação e de um treinamento moral, os afroamericanos conseguiriam se integrar na sociedade e outros achavam que a solução era $o$ reassentamento dos negros no Caribe ou em colônias na África ${ }^{7}$. A participação dos quakers na colonização da Libéria foi bastante expressiva, seja pelas diversas contribuições financeiras com a American Colonization Society desde a sua fundação ${ }^{8}$ ou através da contribuição do quaker afroamericano Paul Cuffe (1758 - 1817), que transportou com recursos próprios negros de Boston para Serra Leoa e sugeriu a um membro da ACS que os Estados Unidos fundassem uma colônia para os

$4 \quad$ ZUBERI, Tukufu. Op. Cit. p. 68

5LIBERIAN LETTERS: Terrell's 1854 Will. In: http://search.lib.virginia.edu/catalog/uva-lib:501787

6APTHEKER, Herbert. The Quakers and Negro Slavery. The Journal of Negro History, Vol. 25, No. 3 (Jul., 1940), pp. 331-362.

7BACON, Margaret Hope. Quakers and Colonization. Quaker History, Vol. 95, No. 1 (Spring 2006), p. 26. 8Ibidem, p. 27. 
negros na África ${ }^{9}$. Ambas as posições dos quakers diante da escravidão revelam a influência das teorias racialistas do século XIX dentro da Sociedade Religiosa dos Amigos, e nos permitem dizer que é pouco provável que James H. Terrell tenha libertado seus escravos por motivos religiosos.

Era comum que alguns senhores de escravos libertassem alguns de seus escravos nos seus testamentos, como Thomas Jefferson fez em 1826, porém é provável que a vontade de James $\mathrm{H}$. Terrell de libertar todos os seus escravos pode estar ligada ao fato de que ele e sua esposa não terem tido filhos e seu sobrinho James Hunter Minor ter sido nomeado seu herdeiro. É dito que ele adotou seu sobrinho ${ }^{10}$, mas o fato é que não tendo um herdeiro direto, James Hunter Terrell não se preocupou em manter a integridade dos seus bens após sua morte, levando em consideração o prejuízo financeiro que a propriedade de "Music Hall" pode ter sofrido depois da libertação de todos os seus escravos.

James Hunter Minor, herdeiro e executor do testamento, recebeu o prazo máximo de 4 anos para organizar a libertação dos escravos e o assentamento daqueles que gostariam de emigrar para a Libéria. Para isso, James Hunter Terrell deixou a propriedade de "Ducking Hole" para ser vendida a fim de criar um fundo para arcar com os custos da viagem. Ademais, a renda recebida pela venda dos escravos que não quisessem emigrar também deveria ser revertida para esse fundo ${ }^{11}$.

\section{A jornada de William Douglass}

William Douglass foi um dos escravos de James Hunter Terrell que foi alforriado e enviado para a Libéria. É curioso ele, escravo, compartilhar o nome com outro negro, o líder abolicionista William Douglass (1804-1862), porém é pouco provável que ele tenha escolhido esse nome para si mesmo. Apesar das discussões sobre o processo de nomeação dos escravos pelos senhores, na maioria dos casos eles recebiam o sobrenome do seu senhor e, apesar de alguns trocarem o nome quando eram alforriados, grande parte os mantinham depois de livres. No caso de William podemos tentar identificar, através das fontes que temos acesso, que o sobrenome Douglass indica que ele provavelmente nasceu na propriedade de "Ducking Hole", que pertenceu ao Rev. William Douglas e foi herdada pela mãe de James H. Terrell ${ }^{12}$. Ao receber ou comprar novos 9Ibidem, p. 5-6.

10 DICKEN, Emma. Terrell Genealogy. San Antonio, Texas: The Naylor Company, 1952.p. 188-189. In: http://www.terrellsociety.com/genealogy/documents/L013 Dicken_withNewIndex_S.pdf

11 LIBERIAN LETTERS: Terrell's 1854 Will. In: http://search.lib.virginia.edu/catalog/uva-lib:501787

12 DICKEN, Emma. op. cit. 
escravos era comum que os senhores de escravos mantivessem o sobrenome do antigo senhor a fim de facilitar a diferenciação entre o novo escravo e aqueles que já estavam na propriedade ${ }^{13}$. Sendo assim, é possível que quando a propriedade de "Ducking Hole" foi incorporada por James H. Terrel, ele tenha decidido manter os nomes dos novos escravos. Se essa tiver sido uma prática comum dele, isso também explicaria porque havia uma grande variedade de sobrenomes entre os expatriados de "Music Hall".

James Hunter Terrell morreu em 07 de abril de 1856. Apesar do prazo de 4 anos dado ao sobrinho para enviá-los para a Libéria, em 08 de dezembro de 1856, seu herdeiro James Hunter Minor enviou um grupo de pessoas através do navio da ACS Mary Caroline Stevens ${ }^{14}$. William Douglass informou que todos emigrados chegaram são e salvos e o nomeia 21 deles, entre os quais estão, além dele mesmo, sua esposa Susan, e Mary Douglass sua filha, Thos. Scott, David Scott, Chas. Twin, Phil Twin, Geo. Walker, Hugh Walker, Jr., Winzer Walker, Wilson Coleman, Washington Coleman, Martin Coleman, Allen Coleman, Young Barrett, Maria Barrett, Isabella Johnson, Chas. Barrett, Dick Barrett, John Mickey, and Washington Mickey ${ }^{15}$. Há outros correspondentes e nomes citados em cartas para James H, Minor que não estão nessa lista de Douglass. Na sua primeira carta para o Dr. James H. Minor, William Douglass também contou que a travessia de Norfolk (Virgínia) para o Grand Cape Mount foi tediosa, eles foram para a Monróvia e depois, e ele as demais 21 pessoas citadas, foram convidados pelos Rev. John Seys a fazer parte de um experimento e irem para um assentamento perto do rio St. Paul, posteriormente nomeado Careysburgh, mais no interior do território, onde havia mais área cultivável, recursos exploráveis, como madeira e onde acreditava que poderiam ficar mais protegidos das febres tropicais por causa da altitude ${ }^{16}$.

13 PATERSON, David E. A Perspective on Indexing Slaves' Names. The American Archivist, Vol. 64 (Spring/Summer 2001) : 132-142. In: http://americanarchivist.org/doi/pdf/10.17723/aarc.64.1.th18g8t6282h4283? code=same-site

14 AFRICAN REPOSITORY. Volume 34, nº 2, 1858. p. 45.

15 LIBERIAN LETTERS: William Douglass to Dr. James H. Minor, 1857, February 5. In: http://search.lib.virginia.edu/catalog/uva-lib:501744

16 LIBERIAN LETTERS: Young Barrett, Maria Barrett, and Isabella Johnson to Dr. James H. Minor, 1857, March 3. In: http://search.lib.virginia.edu/catalog/uva-lib:501746 


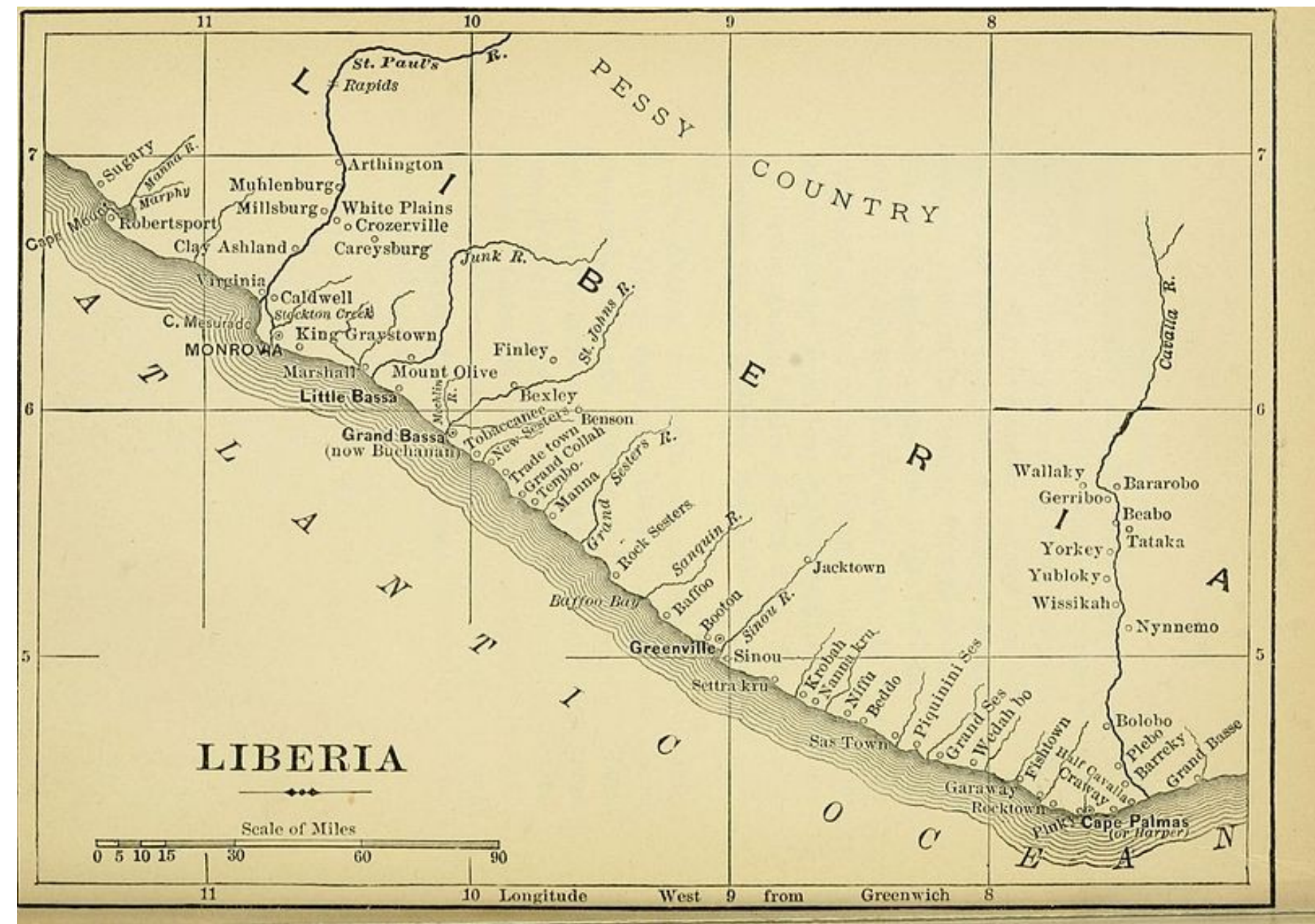

Missions and missionary society of the Methodist Episcopal Church"(Missões e sociedade missionária da Igreja Episcopal Metodista. Ano: 1895 (1890s). Autores: Reid, J. M. (John Morrison), 1820-1896 Gracey, J. T. (John Talbot), 1831-1912 .

As boas impressões sobre o novo lar foram expressadas não apenas por William Douglass em sua carta, também por Mary Michie que fala sobre a chegada na Monróvia e seu alívio por todos da família terem chegado bem, bem como, sua surpresa em relação ao clima quente da Libéria. Michie narra seu encontro com um conhecido, membro da família Paxton, que havia emigrado para a Libéria alguns anos antes ${ }^{17}$. Isso evidencia que havia um grande número de emigrados provenientes do Estado da Virgínia na Libéria ${ }^{18}$, afinal este foi o Estado que mais expatriou negros e o motivo pode estar conectado ao medo que se instaurou entre os brancos depois da rebelião de Nat Turner em $1831^{19}$.

17 LIBERIAN LETTERS: Mary Michie to Dr. James H. Minor, 1857, February 4. In: http://search.lib.virginia.edu/catalog/uva-lib:501743

18 A Universidade da Virgínia identificou em documentos cerca de 3.700 pessoas que emigraram entre 1820 e 1867. In: http://www.vcdh.virginia.edu/liberia/index.php?page=Home

19 ZUBERI, Tukufu. op. cit. p. 55. 
Na primeira carta, Douglass afirma que eles e seus colegas não conseguiram retirar do navio Mary Caroline Stevens alguns itens que levaram para a Libéria Em uma carta coletiva, ele e outros emigrados solicitam vários itens, desde comida até produtos manufaturados como roupas e sapatos, e ressaltando que estavam assentados a 15 milhas da Monróvia, com crianças e assombrados pela possibilidade de pegar uma febre ${ }^{20}$. Praticamente em todas as cartas enviadas para James H. Minor, de William Douglass e dos outros expatriados enviados por Minor, havia uma lista de itens a serem enviados para os emigrados, entre os mais pedidos havia barris de farinha, açúcar e porco, roupas, tecido de algodão, sapatos, utensílios domésticos e ferramentas de trabalho, pólvora, peixe, dinheiro vivo, tabaco, entre outros. Geralmente eles pediam para serem embarcados no Mary Caroline Stevens, navio que era propriedade da ACS e fazia viagens constantes entre a Libéria e os Estados Unidos. Em uma carta Hugh Walker relatou a demora no recebimento dos itens solicitados e que desconfiava que talvez eles estivessem sendo roubados ${ }^{21}$. Obviamente, havia uma grande dificuldade em se encontrar produtos manufaturados na Libéria e os esforços de plantio no solo demoraram para dar resultados, portanto como estavam no início da sua adaptação na Libéria, os expatriados de "Music Hall" eram extremamente dependentes dos produtos enviados dos Estados Unidos, isso é demonstrado pela urgência e quantidade de itens requisitados. Os américo-liberianos importavam uma grande quantidade de produtos dos Estados Unidos e Europa, além de comprarem produtos agrícolas de tribos nativas ${ }^{22}$.

A alta taxa de mortalidade entre os emigrados para Libéria parece não ter atingido os expatriados que foram para Careysburg. Posteriormente, isso levou o assentamento a ser considerado um grande sucesso ${ }^{23}$. Porém, em suas cartas, os expatriados sempre relatavam várias mortes daqueles que viajaram com eles e haviam se assentado em Clay Ashland ou na Monróvia, provavelmente para que os parentes que ficaram nos Estados Unidos pudessem ser avisados. William Douglass diz em uma das suas cartas que achava que pessoas que nasceram em regiões montanhosas não deveriam morar na costa. ${ }^{24}$ Mais tarde, ele, a esposa e a filha tiveram febre tropical, mas todos sobreviveram.

As cartas dos emigrados de "Music Hall" mostram que, apesar de estarem

20 LIBERIAN LETTERS: William Douglass, Hugh Walker, and Samuel Carr to Dr. James H. Minor, 1857, February 6. In: http://search.lib.virginia.edu/catalog/uva-lib:501745

21 LIBERIAN LETTERS: Hugh Walker to Dr. James H. Minor, March 4, 1857 . In: http://search.lib.virginia.edu/catalog/uva-lib:501747

22 ZUBERI, Tukufu. op. cit. p. 68.

23 FORTY-SECOND ANNUAL REPORT of the American Colonization Society. January 18, 1859. p. 14.

24 LIBERIAN LETTERS: William Douglass to Dr. James H. Minor and Frank Nelson, 1857, March 8. In: http://search.lib.virginia.edu/catalog/uva-lib:501749 
prosperando em Careysburg, eles tinham muitos parentes e amigos que ficaram nos Estados Unidos e as correspondências com James Hunter Minor era uma forma de conservar, ainda que superficialmente, esses laços. Não sabemos se eles ficaram porque não eram escravos da propriedade de "Music Hall”, mas pertenciam a alguém da família Terrell, ou porque não quiseram ou puderam viajar. O fato é que as cartas dos expatriados eram repletas de saudações e buscas por notícias daqueles que ficaram, Hugh Walker, por exemplo, deixou sua mãe e pai e pedia para ser avisado caso eles ou algum amigo morresse ${ }^{25}$. William Douglass sempre mandou lembranças para seus amigos em suas cartas, sobre seus familiares que ficaram nos EUA, identificamos sua velha tia Rachel. Ele disse em uma carta estar aliviado por sua tia não ter atravesssado o Atlântico porque estava muito velha para os desafios da vida na Libéria ${ }^{26}$ e escreveu uma vez para ela lamentando a distância entre eles ${ }^{27}$. Além disso, quando já estava comercializando mercadorias, Douglass enviou a quantia de 50 dólares para ser dividida igualmente em 10 dólares para cada filho que ainda estava na Virgínia, nos levando a entender que ele teve que deixar cinco filhos para trás ${ }^{28}$. Apesar de ser uma forma de obter a liberdade, a expatriação para a Libéria não deixou de ser uma experiência traumática para as pessoas de "Music Hall" que tiveram que encarar o árido caminho da colonização em uma terra distante e abandonar a família e amigos para trás.

\section{O desenvolvimento da agricultura em Careysburg e Clay Ashland.}

Seis meses depois chegar em Careysburg, William Douglass informou que ele e seus companheiros haviam plantado batatas, mandiocas, inhames, tomates, feijão-de-lima ${ }^{29}$, alguns pés de café e outras pequenas coisa em benefício de suas famílias ${ }^{30}$. Os emigrados que ficaram em Clay Ashland também relataram seu sucesso na agricultura, pois plantavam uma grande diversidade de vegetais, entre os quais havia batata, inhame, alguns tipos de arroz, feijão-de-lima, e

\footnotetext{
25 LIBERIAN LETTERS: Hugh Walker to Dr. James H. Minor, 1860, January $20 . \quad$ In: http://search.lib.virginia.edu/catalog/uva-lib:501780

26 LIBERIAN LETTERS: William Douglass to Dr. James H. Minor, 1857, August 19. In:
}

http://search.lib.virginia.edu/catalog/uva-lib:501751

27 LIBERIAN LETTERS: William Douglass to his aunt, 1858, January $28 . \quad$ In: http://search.lib.virginia.edu/catalog/uva-lib:501765

28 LIBERIAN LETTERS: William Douglass to Dr. James H. Minor, 1861, February 22.

http://search.lib.virginia.edu/catalog/uva-lib:501784

29 O Phaseolus lunatus, também conhecido pelos nomes de feijão-de-lima,bonje, feijão-bonje, fava-belém, fava-delima, fava-terra, feijão-espadinho, feijão-farinha, feijão-favona, feijão-fígado-de-galinha, feijão-manteiga, feijãoverde, feijoal e mangalô-amargo.

30 LIBERIAN LETTERS: William Douglass to Dr. James H. Minor, 1857 , August 19. In:http://search.lib.virginia.edu/catalog/uva-lib:501751 
vários tipos de fruta ${ }^{31}$. Além de produzir alimentos para a subsistência, o desenvolvimento da agricultura em Careysburg e Clay Ashland fazia parte de um projeto do governo liberiano para o fortalecimento da economia e expansão das fronteiras para o interior do território ${ }^{32}$.

Em Careysburg, os ex-escravos puderam ter acesso a escolarização. Richard Barrett relata em uma carta que haviam reuniões todos os domingos de manhã na Baptist Association, nas quais os adultos e crianças poderiam aprender a ler e escrever ${ }^{33}$. William Douglass revela em uma das suas cartas que estava aprendendo, mas ainda não conseguia escrever uma carta ${ }^{34}$, nos revelando que não era ele que escrevia cartas. Isso demonstra que, apesar dos discursos de que a colonização da Libéria seria para instruir e 'civilizar' os nativos, a maior parte dos expatriados era formada por analfabetos que também precisavam de instrução. Dessa forma, ainda no início de 1843, os emigrados já haviam desenvolvido um sistema educacional com a ajuda de muitas sociedades missionárias ${ }^{35}$ para atendê-los e, assim como, aos nativos.

Além de fazendeiro, William Douglass se tornou também um comerciante, vendendo batata, mas também tinha pés de café florescendo e uma pequena colheita de tabaco ${ }^{36}$. Provavelmente, o café foi introduzido na Libéria por marinheiros portugueses que exploraram a costa liberiana em busca da pimenta-da-guiné. Entre 1861 e 1865, houve um aumento no preço do café que levou a Libéria a se tornar uma exportadora de café, apesar dele já ser cultivado desde $1830^{37}$. Douglass estava na vanguarda do mercado e provavelmente ganhou muito dinheiro com essa escalada no preço de café.

Em 1861, William Douglass já estava bem estabelecido como comerciante, possuía uma loja, provavelmente na Monróvia, e já conseguia enviar dinheiro para seus filhos que ficaram para trás. Ele disse estar financeiramente bem e informou seu desejo de ir aos Estados Unidos. Ao relatar as notícias do restante da comunidade informou que todos os homens jovens tiveram que ir para

31 LIBERIAN LETTERS: Tibby Scott to Dr. James H. Minor,1858, January 8. In:http://search.lib.virginia.edu/catalog/uva-lib:501753

32 SAHA, Santosh C.Agriculture in Liberia during the Nineteenth Century: Americo-Liberians' Contribution.Canadian Journal of African Studies / Revue Canadienne des Études Africaines, Vol.22, No. 2 (1988), p. 233.

33 LIBERIAN LETTERS: Richard Barrett to Elizabeth Lewis, 1858, January 28.

In: http://search.lib.virginia.edu/catalog/uva-lib:501761

34 LIBERIAN LETTERS: William Douglass to Dr. James H. Minor ,1859, January 26.

In: http://search.lib.virginia.edu/catalog/uva-lib:501771

35 ZUBERI, Tukufu. op. cit. p. 72.

36 LIBERIAN LETTERS: William Douglass to Dr. James H. Minor ,1859, January 26.

In: http://search.lib.virginia.edu/catalog/uva-lib:501771

37 ALLEN, William E. op. cit. p.41 - 43. É importante ressaltar que na virada do século a maioria dos fazendeiros havia abandonado a produção de café depois queda no mercado e nos preços. 
Cape Palmas, em Maryland County, a fim de se unirem ao $4^{\mathrm{o}}$ regimento e atacar forças hostis ${ }^{38}$. No período 1847 a 1877, a política do governo liberiano de expansão para o interior fez emergir diversos conflitos com as populações nativas ${ }^{39}$, entre o mais importantes havia o conflito dos povos Grebos e os Krus contra os moradores de Maryland County. Segundo as autoridades da Libéria, os Grebos e Krus reagiram contra as políticas anti-escravistas tomadas pelo governo na região ${ }^{40}$ e é proável que os expatriados de Careysburg tenham sido recrutados para lutarem nesses conflito.

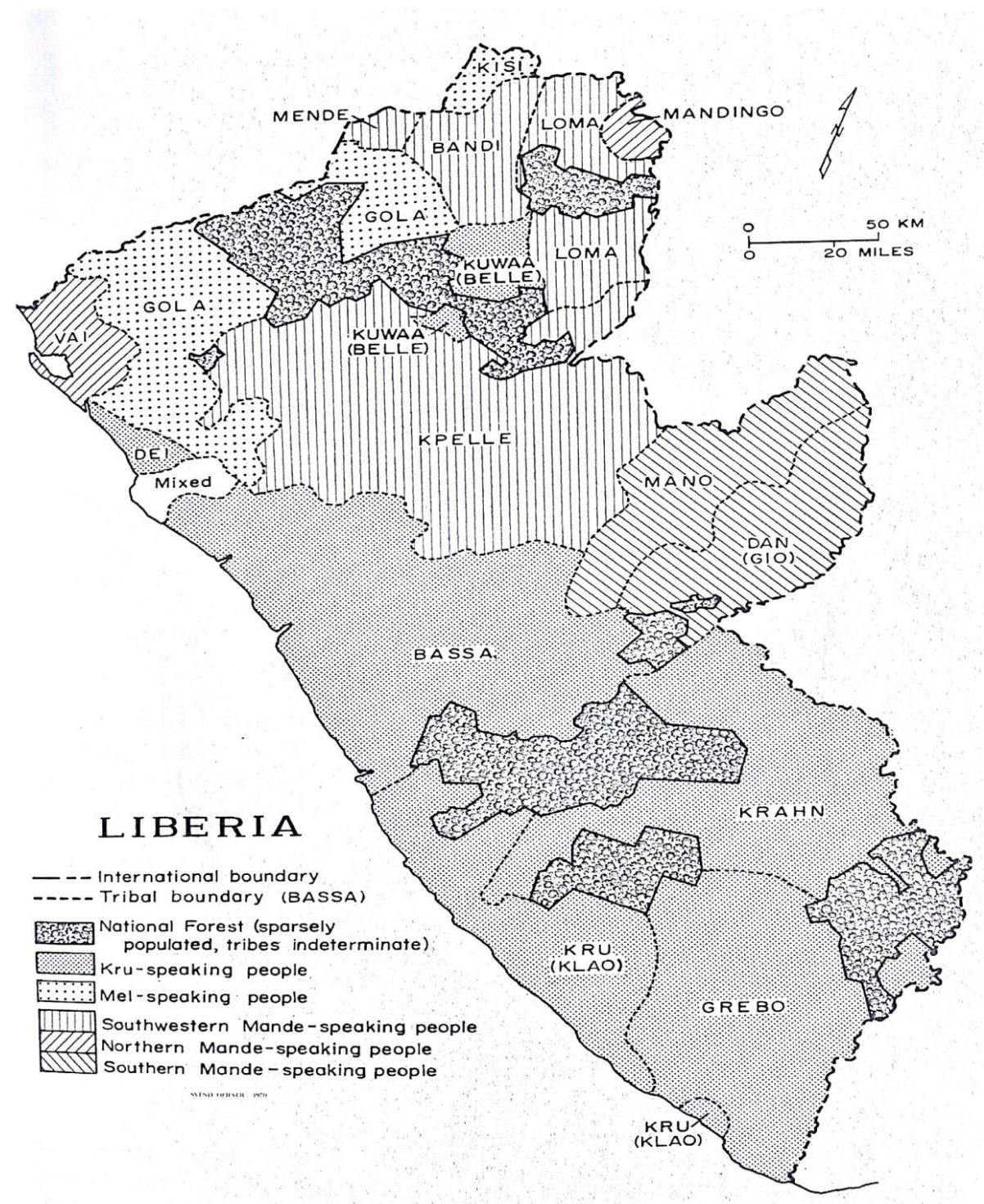

38 LIBERIAN LETTERS: William Douglass to Dr. James H. Minor, 1861, February 22.

In: http://search.lib.virginia.edu/catalog/uva-lib:501784

39 LEVITT, Jeremy I.The Rise of a Settler Oligarchic State, 1847-1877. In: The evolution of deadly conflict in Liberia : from ‘paternaltarianism' to state collapse. Carolina Academic Press: Carolina Norte, EUA, 2005. p. 89 - 124.

40 LOWENKOPF. op. cit. p. 33. 
Distribuição dos principais grupos étnicos e linguísticos liberianos. ${ }^{41}$

Depois de um hiato de quatro anos, Douglass enviou uma nova carta para James H. Minor pedindo notícias já que não conseguiram se falar durante o período da Guerra Civil, ou Guerra da Secessão, (1861-1865). Ele pergunta sobre a saúde de James Minor e de seus familiares e solicita notícias dos seus filhos, dizendo que em breve espera conseguir trazê-los para a Libéria. William Douglass relata a chegada de cerca de 340 emigrados da ilha de Barbados, alguns do quais estavam vivendo em Careysburg, ademais informa que estava indo muito bem nos negócios e havia ganho 8.000 libras naquele ano com a venda de açúcar ${ }^{42}$.

A Guerra Civil norte-americana alterou fortemente as relações entre Estados Unidos e Libéria. Durante e após a guerra, a partir do vislumbre e com a concretização da abolição da escravidão, o interesse dos negros norte-americanos em ir para a Libéria sofreu uma grande queda ${ }^{43}$. Edward Blyden, nessa época professor no Liberia College, percebeu que os norte-americanos estavam desistindo de emigrar e decidiu voltar sua atenção para o Caribe. Ele persuadiu a American Colonization Society a desembolsar 10.000 dólares pela causa e, em 6 de Abril de 1865, o navio "Cora" deixou a ilha de Barbados com 346 imigrantes voluntários, selecionados por suas habilidades, que foram assentados em Careysburg ${ }^{44}$. A produção de açúcar foi muito lucrativa durante a Guerra da Secessão ${ }^{45}$, podemos perceber isso com quantia que William Douglass ganhou em 1865. Porém, a inserção dos emigrados de Barbados foi importante para a melhoria das técnicas de plantio e produtividade que transformou o açúcar em grande produto de exportação ${ }^{46}$. Posteriormente, os emigrados de Barbados fundaram um assentamento Crozerville, perto de Careysburg, onde também produziam gengibre e $\operatorname{araruta}^{47}$.

A última carta encontrada de William Douglass, datada de 1866, é endereçada a um amigo, mas acredita-se que o destinatário seja James H. Minor. Ele informou seus progressos na Libéria,

41 Ibidem, p. 29.

42 LIBERIAN LETTERS: William Douglass to Dr. James H. Minor, 1865, August 15.

http://search.lib.virginia.edu/catalog/uva-lib:501785

43 DAVIS, Lenwood G. Black American Images of Liberia, 1877 - 1914. Liberian Studies Journal, v. VI, no 1, 1975. p. 54.

44 LYNCH, Hollis. The Pan Negro Goal, Class and Color Conflict in Liberia 1862 - 71. In: Edward Wilmot Blyden: Pan-Negro Patriot, 1832-1912, New York: Oxford University Press, 1967. p. 32 - 53.

45 SAHA, Santosh C. op. cit. p. 237.

46 AKPAN, M. B. The Liberian Economy in the Nineteenth Century: The State of Agriculture and Commerce.Liberian Studies Journal, v. VI, $n^{\circ} 1$ 1975. p. 1-24. O autor ressalta que no final do século XIX o açúcar e café se tornaram atividades menos lucrativas devido ao mercado e concorrência mundial, sendo o que o cultivo deles foi gradativamente abandonado.

47 AFRICAN REPOSITORY. Volume 47, nº 9, 1871, p. 278. 
porém se revelou preocupado com a falta de respostas porque havia enviado outras quatro cartas (provavelmente perdidas) desde o início da Guerra Civil e não obteve respostas. Além disso, ela ansiava confirmar as notícias que ouviu de que dois de seus filhos haviam sido mortos durante a guerra $^{48}$. Douglass se mostrou preocupado de que o próprio James Minor estivesse morto e essa era a realidade, já que ele havia falecido em 1862 na propriedade de "Music Hall"49. É difícil mensurar o impacto da morte de James H. Minor nas relações de William Douglass com seus familiares que ficaram nos Estados Unidos, além disso, a morte dele nos impossibilitou saber mais sobre a jornada de William Douglass na Libéria. Para além das cartas, conseguimos identificar que Douglass também se aventurou no mundo da cartografia e fez um rascunho topográfico de Careysburg que foi encontrado nos documentos da ACS.

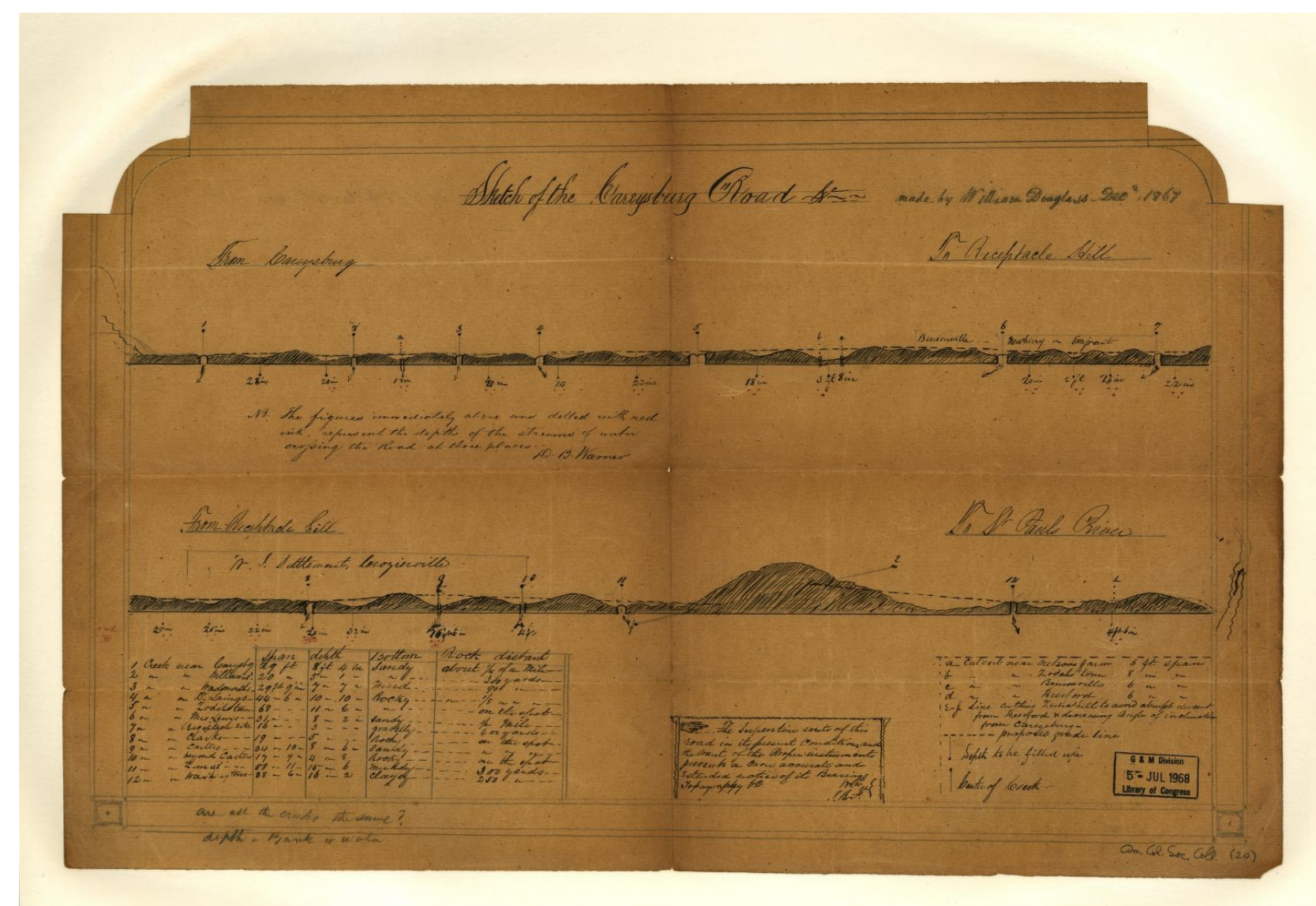

Sketch of the Careysburg Road, \&c. Autor: William Douglass ${ }^{50}$

Antes da organização completa da American Colonization Society, em 1817, alguns negros

\footnotetext{
48 LIBERIAN LETTERS: William Douglass to a Friend, 1866, January 29. In:http://search.lib.virginia.edu/catalog/uva-lib:501786

49 DICKEN, Emma. op. cit. p. 29.

50 Map. Retrieved from the Library of Congress, <https://www.loc.gov/item/96684996/>.
} 
livres, abolicionistas e forros já começavam a se expressar publicamente contra a colonização na Libéria. Entre os descontentes e desconfiados dos propósitos benevolentes da ACS, estava o abolicionista William Douglass, homônimo do biografado. Eles acusavam a participação de escravistas na Associação e defendiam que a emigração reafirmava a desigualdade entre negros e brancos nos Estados Unidos. Para alguns abolicionistas, o movimento de colonização na África era na verdade uma forma de expatriação dos negros, retirando-os do lugar que nasceram e conheceram a vida toda e levando-os para um lugar desconhecido e hostil ${ }^{51}$. De maneira oposta, havia aqueles, entre eles Blyden, que eram a favor do retorno dos negros para África, sua verdadeira terra natal, visto que acreditavam que jamais seriam tratados de forma justa e igualitária dentro do território norte-americano ${ }^{52}$.

Nesse cenário de oposição a colonização, o African Repository and Colonial Journal (18251887), uma revista publicada trimestralmente pela ACS e com os lucros da venda convertidos para causa da Sociedade, foi uma importante forma de propaganda para arrecadamento de fundos e divulgação dos bons resultados obtidos na colônia. Os principais conteúdos das publicações eram os dados administrativos dos navios que levavam os emigrantes, prestação de contas financeiras e de reuniões da ACS, artigos científicos que refutavam a inferioridade dos negros e sobre outras regiões da África, notícias sobre movimentos abolicionistas ao redor do mundo e biografias de grandes personalidades que foram importantes para o estabelecimento da colônia na Libéria.

As biografias do African Repository and Colonial Journal eram caracterizadas pela narrativa dos grandes homens como membros importantes da ACS enviados para a Libéria e negros que foram membros da elite política américo-liberiana. A perspectiva biográfica de William Douglass é importante porque nos deu uma visão daqueles que não participavam da esfera de poder e influência e uma perspectiva dos desafios enfrentados por aqueles emigrados que não tinham grande poder aquisitivo, sendo que a pequena elite liberiana era formada por apenas $12 \%$ da população, que era também a parcela mais bem-educada entre os emigrados ${ }^{53}$. A partir desse contexto histórico liberiano, a biografia de William Douglass pode ser, então, enquadrada como uma biografia de subalterno ${ }^{54}$.

51 MEHLINGER Louis R. The Attitude of the Free Negro Toward African Colonization. The Journal of Negro History, Vol. 1, No. 3 (Jun., 1916), p. 276- 277.

52 LYNCH, Hollis. op. cit.

53 ZUBERI, Tukufu. op. cit. p. 69.

54 LORIGA, Sabina. A biografia como problema. In: REVEL, Jacques (org.). Jogos de escala: a experiência da microanálise. Rio de Janeiro: FGV, 1998, p. 225-49 


\section{Conclusão}

A experiência de vida de William Douglass na Libéria pode ser vista como uma representação da sociedade que ele viveu ${ }^{55}$ e um reflexo dos problemas e dificuldades enfrentadas pelos negros nos Estados Unidos. Apesar de ter sido alforriado, sua possibilidade de escolha estava restrita a tentar a vida na hostilidade do território liberiano ou permanecer escravo nos Estados Unidos. O fato é que, apesar das dificuldades e da alta taxa de mortalidade, a Libéria oferecia a possibilidade de prosperidade com a agricultura ou comércio e tratamento igualitário, o que levou tantos negros a se arriscarem nessa empreitada ${ }^{56}$.

Obviamente, a escassez das fontes foi uma das grandes dificuldades encontradas para reconstituirmos a trajetória de William Douglass, ficamos restritos ao período de tempo abrangido nas suas correspondências com o James H. Minor. Porém, ao analisarmos também as cartas enviados por outros emigrados de "Music Hall" conseguimos identificar um pouco da comunidade organizada por eles em Careysburg ${ }^{57}$. Suas cartas revelam a vulnerabilidade dos emigrando chegavam na Libéria, que refletia a vulnerabilidade da própria Libéria que, mesmo tendo se tornado independente em 1847, continuava economicamente dependente dos Estados Unidos. Apesar de termos acesso apenas às cartas enviadas pelos expatriados, constantemente eles agradeciam nelas as cartas e produtos enviados por James H. Minor, ademais a manifestação de William Douglass de querer ir aos Estados Unidos, revelam que as relações Libéria-EUA foram estabelecidas por fluxos e refluxos de pessoas e mercadorias. Não podemos negar o custo emocional da expatriação, além do sofrimento com as morte dos que emigraram, como na comunidade de Clay Ashland, os expatriados tinham que lidar com a distância e a escassa comunicação com os familiares que permaneceram nos Estados Unidos. A biografia de William Douglass nos mostra não apenas os desafios que ele teve que superar para se estabelecer na Libéria, mas, também, as conexões sociais, comerciais e fraternais, estabelecidas entre Libéria e Estados Unidos no mundo atlântico do século XIX.

\section{Bibliografia}

AKPAN, M. B. The Liberian Economy in the Nineteenth Century: The State of Agriculture and

55 BEZERRA, Nielson Rosa. Escravidão, biografias e a memória dos excluídos. Revista Espaço Acadêmico v. 11, n. 126 (2011) ONLINE

56 DAVIS, Lenwood G. op. cit.. p. 56.

57 LEVI, Giovanni. Usos da biografia. In: AMADO, Janaína; FERREIRA, Marieta de (orgs.). Usos e abusos da história oral. Rio de Janeiro: FGV, 1996, p. 167-82. online 
Commerce. Liberian Studies Journal, v. 6, n. 1, p. 1-24, 1975.

AMERICAN COLONIZATION SOCIETY. Forty-Second Annual Report, p. 14, 1859. Disponível em: https://archive.org/details/ASPC0001926400. Acesso em: 15 nov. 2016.

ANNUAL MEETING OF AMERICAN COLONIZATION SOCIETY 41. Washington. African Repository, v. 34, n. 2, p. 45, 1858. Disponível em: https://babel.hathitrust.org/cgi/pt? id=hvd.hwrchw;view=1 up;seq=1. Acesso em: 23 dez. 2016.

APTHEKER, Herbert. The Quakers and Negro Slavery. The Journal of Negro History, v. 1, n. 3, p.331-362, jul. 1940. Disponível em: http://testfamilygenealogy.com/History/Petition/Articles/2714799.pdf. Acesso em: 24 dez. 2016.

BACON, Margaret Hope. Quakers and Colonization. Quaker History, v. 95, n. 1, p. 26-43, 2006. Disponível em: https://muse.jhu.edu/article/393164. Acesso em: 15 nov. 2016.

BEZERRA, Nielson Rosa. Escravidão, biografias e a memória dos excluídos. Revista Espaço

Acadêmico, v. 11, n. 126, p. 136-144, 2011. Disponível em: http://www.periodicos.uem.br/ojs/index.php/EspacoAcademico/article/view/13126. Acesso em: 15 nov. 2016.

DAVIS, Lenwood G. Black American Images of Liberia, 1877 - 1914. Liberian Studies Journal, v. 6, n. 1, p. 53-73, 1975.

DICKEN, Emma. Terrell Genealogy. San Antonio, Texas: The Naylor Company, 1952, p. 188189.

Disponível

em: http://www.terrellsociety.com/genealogy/documents/L013_Dicken_withNewIndex_S.pdf. Acesso em: 12 out. 2016.

LEVI, Giovanni. Usos da biografia. In: AMADO, Janaína; FERREIRA, Marieta de. (Orgs.). Usos e abusos da história oral. Rio de Janeiro: FGV, 1996, p. 167-182.

LORIGA, Sabrina. A biografia como problema. In: REVEL, Jacques. (Org.). Jogos de escala: a experiência da microanálise. Rio de Janeiro: FGV, 1998, p. 225-249.

LOWENKOPF, Martin. Politics in Liberia: The Conservative Road to Development. Califórnia: Hoover Institution Press, 1976.

LYNCH, Hollis. Edward Wilmot Blyden: Pan-Negro Patriot, 1832-1912, New York: Oxford University Press, 1967.

MEHLINGER, Louis R. The Attitude of the Free Negro Toward African Colonization. The Journal of Negro History, v. 1, n. 3, p. 276- 301, 1916. Disponível em: https://archive.org/details/jstor-3035624. Acesso em: 12 out. 2016.

PATERSON, David E. A Perspective on Indexing Slaves' Names. The American Archivist, v. 64, n.1, p. 132-142, 2001. Disponível http://americanarchivist.org/doi/abs/10.17723/aarc.64.1.th18g8t6282h4283?code=same-site. Acesso em: 12 out. 2016. 
SAHA, Santosh C. Agriculture in Liberia during the Nineteenth Century: Americo-Liberians. Revue Canadienne des Études Africaines, v. 22, n. 2, p. 224-239, 1988. Disponível em: https://www.jstor.org/stable/485903?seq=1\#page_scan_tab_contents. Acesso em 12 out. 2016.

SICKLE, Eugene S. Van. Reluctant Imperialists: The U.S. Navy and Liberia, $1819-1845$. Journal of the Early Republic, v. 31, n. 1, p. 107-134, 2011. Disponível em: http://www.jstor.org/stable/i23392549. Acesso em: 12 out. 2016.

ZUBERI, Tukufu. Swing Low, Sweet Chariot: The Mortality Cost of Colonizing Liberia in the Nineteenth-Century. Chicago: University of Chicago Press, 1995.

\section{Qualificação Acadêmica e Profissional}

A autora é Tainá Elis Santos de Souza, cursando o sétimo período em História na Universidade Federal de Minas Gerais e participante do programa de Iniciação Científica. O artigo foi desenvolvido como parte da disciplina de Biografia de Africanos Modernos, ministrada no último semestre e sob orientação da professora Vanicléia Silva Santos. Para mais informações podese acessar o currículo Lattes no endereço http://lattes.cnpq.br/7163303407709390. 